\title{
Decreased glucose tolerance and plasma adiponectin:resistin ratio in a mouse model of post-traumatic stress disorder
}

\author{
T. R. Castañeda • R. Nogueiras • T. D. Müller • R. Krishna • E. Grant • A. Jones • \\ N. Ottaway - G. Ananthakrishnan • P. T. Pfluger • N. Chaudhary • M. B. Solomon • \\ S. C. Woods • J. P. Herman • M. H. Tschöp
}

Received: 13 August 2010 / Accepted: 25 November 2010 /Published online: 22 December 2010

(C) Springer-Verlag 2010

\begin{abstract}
Aims/hypothesis Obesity and type 2 diabetes are among the most serious health pathologies worldwide. Stress has been proposed as a factor contributing to the development of these health risk factors; however, the underlying mechanisms that link stress to obesity and diabetes need to be further clarified. Here, we study in mice how chronic stress affects dietary consumption and how that relationship contributes to obesity and diabetes.

Methods C57BL/6J mice were subjected to chronic variable stress (CVS) for 15 days and subsequently fed with a
\end{abstract}

T. R. Castañeda

Department of Medicinal and Biological Chemistry,

College of Pharmacy and Center for Diabetes and Endocrine

Research, College of Medicine, University of Toledo,

Toledo, OH, USA

\section{R. Nogueiras}

Department of Physiology, School of Medicine, University of Santiago de Compostela-Instituto de Investigación Sanitaria, CIBER Fisiopatología de la Obesidad y Nutrición (CIBERobn),

$\mathrm{S}$. Francisco $\mathrm{s} / \mathrm{n}$,

Santiago de Compostela, A Coruña, Spain

URL: www.ciberobn.es

T. D. Müller $\cdot$ R. Krishna $\cdot$ E. Grant $\cdot$ N. Ottaway

G. Ananthakrishnan $\cdot$ P. T. Pfluger $\cdot$ N. Chaudhary $•$

M. H. Tschöp $(\square)$

Metabolic Disease Institute, Division of Endocrinology,

Department of Medicine, University of Cincinnati

College of Medicine,

2170 E Galbraith Road,

Cincinnati, OH 45237, USA

e-mail: tschoemh@ucmail.uc.edu

A. Jones $\cdot$ M. B. Solomon $\cdot$ S. C. Woods $\cdot$ J. P. Herman

Metabolic Disease Institute, Department of Psychiatry,

University of Cincinnati,

Cincinnati, OH, USA standard chow or high-fat diet. Food intake, body weight, respiratory quotient, energy expenditure and spontaneous physical activity were measured with a customised calorimetric system and body composition was measured with nuclear magnetic resonance. A glucose tolerance test was also applied and blood glucose levels were measured with a glucometer. Plasma levels of adiponectin and resistin were measured using Lincoplex kits.

Results Mice under CVS and fed with a high-fat diet showed impaired glucose tolerance associated with low plasma adiponectin:resistin ratios.

Conclusions/interpretation This study demonstrates, in a novel mouse model, how post-traumatic stress disorder enhances vulnerability for impaired glucose metabolism in an energy-rich environment and proposes a potential adipokine-based mechanism.

Keywords Adiponectin - Glucose tolerance - High-fat diet . Mouse $\cdot$ Post-traumatic stress disorder $\cdot$ Resistin
Abbreviations
CVS Chronic variable stress
GTT Glucose tolerance test
HPA Hypothalamic-pituitary-adrenal
PTSD Post-traumatic stress disorder
SPA Spontaneous physical activity

\section{Introduction}

Obesity and type 2 diabetes are worldwide health threats. Of the myriad factors thought to be responsible for these metabolic disorders in our society, chronic stress is among the most prevalent [1]. Stress-induced hypercortisolism, 
upregulation of the hypothalamic-pituitary-adrenal (HPA) axis and downregulation of the sympathetic nervous system have each been proposed to contribute to the prevalence of these pathologies [2, 3], although the mechanism(s) by which stress leads to obesity and insulin resistance has yet to be determined.

Post-traumatic stress disorder (PTSD), a specific type of anxiety disorder, has an estimated lifetime prevalence of 8 $26 \%$ in the general population [4-6] and $15-31 \%$ in war veterans [7-12]. PTSD is a risk factor for diabetes [13, 14], and the prevalence of diabetes is significantly higher in patients with PTSD than in age-matched males in the general population [15]. Consistent with this, veterans of the Vietnam War with PTSD have higher plasma lipid levels than controls [16]. PTSD is also a risk factor for diabetes. In the USA, $76 \%$ of male veterans with PTSD are overweight or obese, compared with $65 \%$ in the US population [17].

With an increasing number of veterans now returning from combat operations, understanding the relationship between mental health and obesity has become a major priority, i.e. whereas the correlation between PTSD and obesity/type 2 diabetes is clear, the mechanisms underlying this association are not. That said, it is reasonable to hypothesise that neuroendocrinological changes induced by stress exposure, specifically activation of the HPA axis and/or the sympathetic nervous system, may contribute to the prevalence of reduced insulin sensitivity [2,3] and type 2 diabetes [18, 19].

Stress is associated with changes in feeding behaviour and food preference; specifically, exposure to stress leads to higher fat and sugar intake [20-23]. Compounding the problem, consumption of a high-fat diet exacerbates the stress-induced HPA-axis response, including elevation of glucocorticoids [24]. Finally, numerous studies suggest that chronic activation of the stress system, in the presence of a fat-enriched diet, results in increased visceral adiposity and insulin resistance reminiscent of Cushing's syndrome [3, 25-28].

To begin to determine the direction of causality, we generated a mouse model of PTSD. We hypothesised that mice that had undergone chronic stress would be more prone to increased consumption of a high-fat diet and the development of obesity and diabetes. We used exposure to a nonhabituation chronic stress regimen (chronic variable stress [CVS]) and assessed the development of obesity and insulin resistance in mice subsequently exposed to a hyperenergetic or control environment. Mice exposed to CVS and fed a highfat diet, but not mice fed a standard chow diet, had impaired glucose tolerance associated with low plasma adiponectin: resistin ratios and showed higher expression of genetic markers of adipogenesis, adipocyte differentiation, hypoxia and inflammation in retroperitoneal adipose tissue. To our knowledge, this is the first demonstration of prejudicial effects on glucose metabolism effected by a fat-enriched diet in a mouse model of chronic stress.

\section{Methods}

Animals C57BL/6J male mice (12 weeks old, Jackson laboratories, Bar Harbor, ME, USA) were singly housed under a $12 \mathrm{~h}$ light-dark cycle (lights on at 06:00 hours) with ad libitum access to low-fat chow (LM485 HarlanTekland Laboratory Diets, Madison, WI, USA) or a $40 \%$ high-fat diet (D03082706 Research Diets, New Brunswick, NJ, USA) and tap water. Mice were singly housed in order to make precise longitudinal measurements of food intake and energy expenditure feasible. All animal protocols were approved by the University of Cincinnati Institutional Animal Care and Use Committee.

Energy balance and body composition measurements Mice were placed for 4 days for adaptation in a customised indirect calorimetry system (TSE Systems, Bad Homburg, Germany), with a flow rate of $0.5 \mathrm{l} / \mathrm{min}$ as previously described by Nogueiras et al. [29]. Measurements of food intake, spontaneous physical activity (SPA), respiratory quotient and energy expenditure were taken at baseline while mice were maintained on chow, 4-6 days after exposure to CVS and after 1 month on a chow or high-fat diet. All energy-balance variables were monitored simultaneously online [30], food intake was recorded every $30 \mathrm{~min}$ and SPA, respiratory quotient and energy expenditure were recorded every $45 \mathrm{~min}$.

Body composition measurements were taken using nuclear magnetic resonance (Whole Body Composition Analyzer; Echo NRI, Houston, TX, USA) at the beginning of the study, after 15 days exposure to CVS and after 1 month of the low-fat or high-fat diet.

CVS Mice were subjected to a series of randomly alternating stressors (administered twice daily) over a period of 15 days [31, 32]. Individual timing of the stressors was selected on the basis of the stress duration required to provoke an adrenocortical response [33] without endangering the animals' well-being. The alternating stressor paradigm is designed to prohibit adaptation to any individual stressor. Stressors employed were: (1) $1 \mathrm{~h}$ in individual cages (minus bedding) in a cold room $\left(4^{\circ} \mathrm{C}\right) ;(2)$ 20 min warm swim $\left(31-33^{\circ} \mathrm{C}\right)$; (3) $1 \mathrm{~h}$ in individual cages on a shaker, causing vibration stress; (4) $30 \mathrm{~min}$ in a hypoxia chamber ( $8 \%$ oxygen/ $92 \%$ nitrogen, vol./vol.); and (5) overnight in large-cage housing.

Glucose tolerance test (GTT) Mice were fasted overnight and then injected intraperitoneally with $2 \mathrm{~g}$ glucose $/ \mathrm{kg}$ body weight $(50 \% \mathrm{wt} / \mathrm{vol}$. D-glucose [Sigma, St Louis, MO, USA] in $0.9 \% \mathrm{wt} / \mathrm{vol}$. NaCl). Tail blood glucose levels $[\mathrm{mmol} / \mathrm{l}]$ were measured with a glucometer (TheraSense Freestyle) before ( $0 \mathrm{~min}$ ) and at 15, 30, 45, 60, and $120 \mathrm{~min}$ after injection. 
Plasma analysis Mice were killed by decapitation at the end of the study and blood was collected and immediately chilled on ice. After $15 \mathrm{~min}$ of centrifugation at $3,000 \mathrm{~g}$ and $4^{\circ} \mathrm{C}$, plasma was stored at $-80^{\circ} \mathrm{C}$. Plasma analysis was also done in samples from tail bleeding after CVS and consumption of the diet for 1 month (Fig. 1). NEFA levels were measured in duplicate using a commercially available enzymatic assay kit (Autokit NEFA C, Wako, Neuss, Germany), triacylglycerol levels were determined in duplicate using Infinity Triglyceride reagent $b$ (Thermo Electron, Pittsburgh, PA, USA) and plasma glucose was measured in duplicate using a commercial kit based on the glucose oxidase method (Biomerieux, Marcy l'Etoile, France). Plasma adiponectin, resistin, insulin and leptin levels were determined with a commercially available Multiplex Luminex xMAP assay (Millipore, Billerica, MA, USA) and mouse Lincoplex kits (Linco Research, St Charles, MO, USA). Intra- and inter-assay coefficients of variation were: $<5 \%$ and $<12 \%$, respectively, for adiponectin; $<4.5 \%$ and $<10.3 \%$, respectively, for resistin; $2.7-5.8 \%$ and $3.8-$ $10.8 \%$, respectively, for insulin; and $<7 \%$ and $<23 \%$, respectively, for leptin. The panel of $\mathrm{T}_{3}, \mathrm{~T}_{4}$ and thyroid stimulating hormone (TSH) were measured using 3 Plex rat thyroid assays (Linco Research, St Charles, MO, USA) and the intra- and inter-assay coefficients of variation were $<10 \%$ and $<5 \%$, respectively. Plasma corticosterone levels were measured in duplicate using a ${ }^{125}$ I radioimmunoassay kit from MP Biomedicals (Orangeburg, NY, USA). Intraand inter-assay coefficients of variation for corticosterone were $<10 \%$. Plasma glycerol levels were measured in duplicate using a commercially available enzymatic assay kit from Sigma. All assays were performed according to the manufacturers' instructions.

Low-density array The expression of 43 genes implicated in carbohydrate, lipid, protein and steroid metabolism, inflammation, cell regulation, proliferation, differentiation, adhesion and migration was analysed in retroperitoneal white adipose tissue samples by real-time PCR using TaqMan Low Density
Arrays (Applied Biosystems, Foster City, CA, USA). Relative expression was measured using the 7900HT TaqMan Fast Real-Time PCR System (Applied Biosystems). PCR reactions were performed in $2 \mu \mathrm{l}$ wells, with each of the 384 wells of the reaction card loaded with the specific primers and probes. The sequences of the primers and probes used were designed and validated by Applied Biosystems and were taken from the Assay-on-Demand mouse library. The specific identification numbers of the Taqman probes (Applied Biosystems) can be obtained from the authors. The relative expression level of each gene was normalised by the geometric average of $18 \mathrm{~S}$ expression.

Morphometric analysis of adipocyte cell size Adipocyte cell size was determined by examining haematoxylin/eosinstained histological sections of inguinal white adipose tissue. Morphometric analysis was performed by measuring 20 cells per mouse, and by quantifying average cell sizes with the ImageJ software (National Institutes of Health, Bethesda, MD, USA, http://rsb.info.nih.gov/ij/).

Adrenal weight Mice were killed at the end of the study and the left adrenals were removed and immediately weighed.

Statistical analyses Quantitative data are presented as mean \pm SEM. Values were analysed for statistically significant differences applying one and two-way ANOVA and Tukey's post hoc tests or two-tailed unpaired $t$ tests. $p<0.05$ was considered significant (GraphPad Prism, GraphPad Software, La Jolla, CA, USA; SigmaStat, Systat Software, San Jose, CA, USA).

\section{Results}

Exposure to CVS transiently decreases lean mass and $S P A$ C57BL/6 male mice were exposed to CVS for 15 days,
Fig. 1 Experimental protocol. Body composition and energy balance variables were measured in $\mathrm{C} 57 \mathrm{BL} / 6$ male mice before and after exposure to CVS for 15 days, and after chronic exposure to chow or a $40 \%$ highfat diet for 1 month. HFD, highfat diet
Body composition measurement Calorimetry adaptation

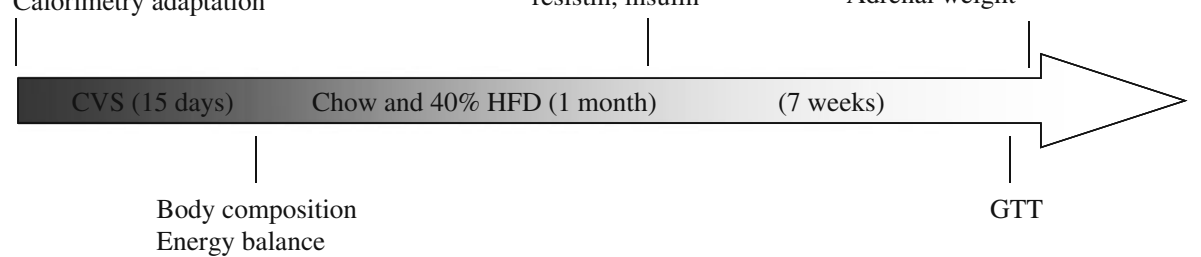

Energy balance

Plasma corticosterone,

triacylglycerols, glucose 
and body composition and energy balance were analysed. Subsequently, mice from the CVS group and a non-stressed control group were each distributed into two subgroups maintained on low-fat chow or a $40 \%$ high-fat diet for 1 month. Body composition and energy balance were then redetermined (Fig. 1). After 15 days' exposure to CVS, mice had significantly lower body weight (Fig. 2a; 26.5 \pm $0.3 \mathrm{~g}, n=16, p<0.001$ ) and lean mass (Fig. $2 \mathrm{c} ; 21.7 \pm 0.3 \mathrm{~g}$, $n=16, p<0.001)$ compared with unstressed controls $(n=15$; $27.9 \pm 0.3 \mathrm{~g}$ and $23.1 \pm 0.2 \mathrm{~g}$, respectively). Fat mass (Fig. 2b) and food intake normalised per g body weight were unaltered (Fig. 2d). The respiratory quotient was significantly decreased during the first dark phase $0.77 \pm$ 0.01 in the CVS mice $(n=15, p<0.01)$ vs $0.82 \pm 0.01$ in the control mice $(n=15)$, but no differences were found at later points (Fig. 2e). There were no significant differences between the groups in energy expenditure levels $(n=15$; Fig. 2f).

The 4 day total SPA levels were significantly decreased in the CVS mice $(75,308 \pm 2,909$ events, $n=16, p<0.001)$ compared with the control group $(108,090 \pm 4,966$ events, $n=15$; Fig. 3).

Plasma measurements were taken the day after the CVS period. Fasting plasma glucose levels were significantly lower in the CVS mice $(7.2 \pm 0.25 \mathrm{mmol} / 1, n=15, p<0.001)$ compared with the control mice $(8.9 \pm 0.32 \mathrm{mmol} / \mathrm{l}, n=15)$. Plasma triacylglycerols were significantly lower in the CVS mice $(0.5771 \pm 0.02304 \mathrm{nmol} / \mathrm{l}, n=15, p<0.05)$ compared with the control mice $(0.6662 \pm 0.02784 \mathrm{nmol} / \mathrm{l}, n=14)$. Plasma corticosterone was already normalised by the end of the stress exposure, as there were no significant differences between the groups at that time (control mice $455.5 \pm$ $17.40 \mathrm{nmol} / \mathrm{l}$, CVS mice $575.3 \pm 30.67 \mathrm{nmol} / 1, n=14-15$ ).

Previous CVS exposure does not affect obesity onset with a high-fat diet As expected, consumption of a $40 \%$ high-fat diet for 1 month increased body weight in the control (32.45 \pm $1.27 \mathrm{~g}, p<0.01, n=8)$ and in the CVS mice $(31.28 \pm 1.05 \mathrm{~g}$, $p<0.01, n=8$ ), as well as fat mass (control mice $6.16 \pm 1 \mathrm{~g}$, CVS mice $5.33 \pm 0.74 \mathrm{~g}, p<0.01, n=8$ ), compared with mice
Fig. 2 Effects of CVS on body composition in C57BL/6 male mice. Mice subjected to CVS (black bars, $n=16$ ) had significantly lower body weight (a) and lean mass (c) compared with the control mice (white bars, $n=15$ ) with no changes in fat mass (b). There was no change in food intake between the CVS mice (grey symbols) and the control mice (white symbols) (d). The respiratory quotient was transiently decreased in the CVS mice compared with the controls during the first dark phase (e). There was no change in energy expenditure in CVS mice compared with the control mice (f). Two-tailed unpaired $t$ test and two-way ANOVA $* * p<0.01$, $* * * p<0.001$
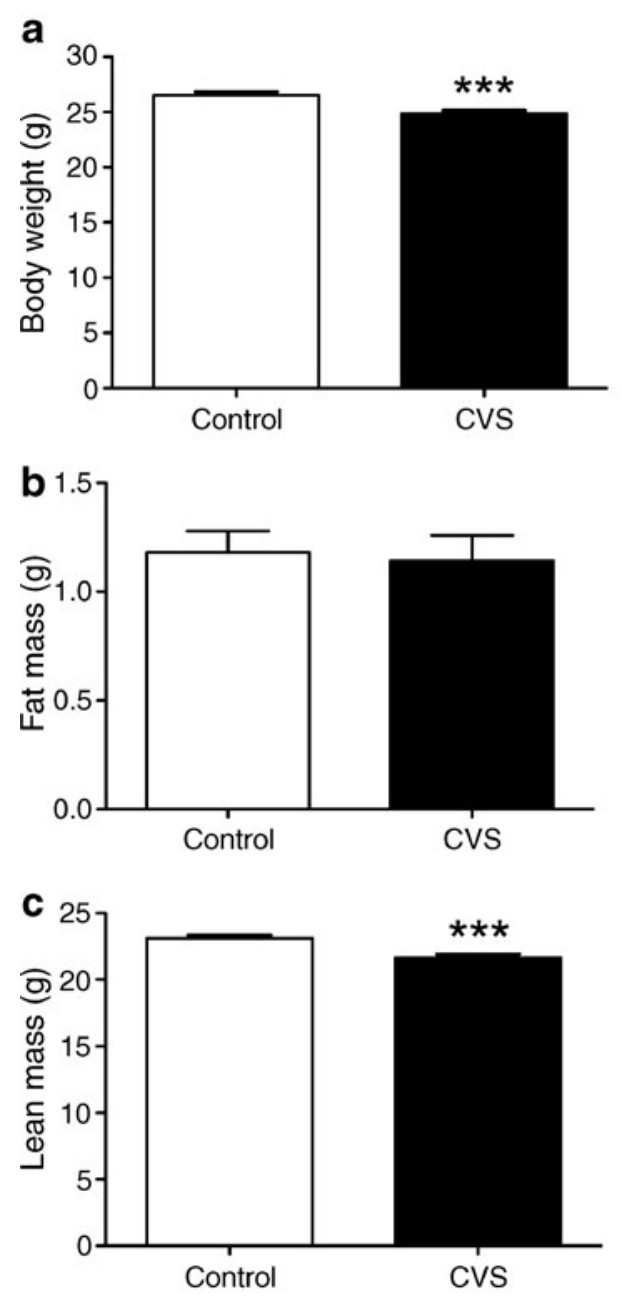
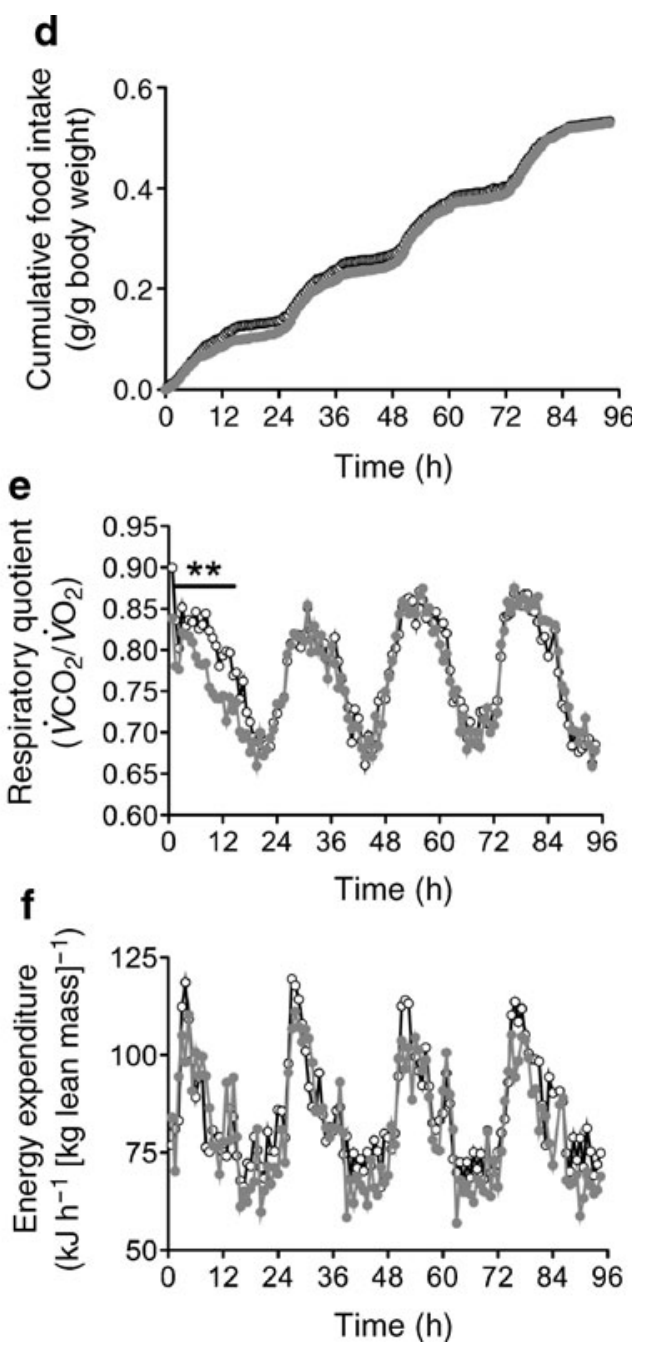
Fig. 3 Effects of CVS on SPA in $\mathrm{C} 57 \mathrm{BL} / 6$ male mice. Mice subjected to CVS (black bars/grey symbols, $n=16$ ) had significantly lower 4 day SPA compared with the control mice (white bars/white symbols, $n=15$ ). (a) SPA over the time during the 4 day assessment time. (b) Total SPA. Two-tailed unpaired $t$ test $* * * p<0.001$

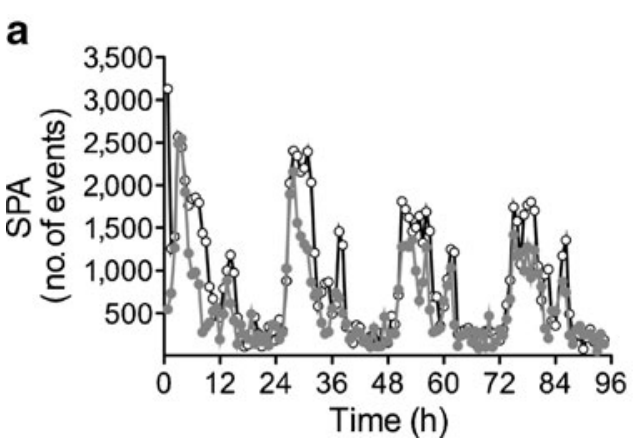

b

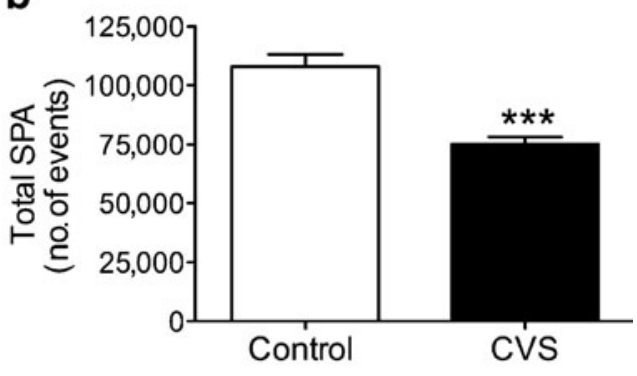

consuming low-fat chow (control mice body weight $27.37 \pm$ $0.62 \mathrm{~g}$ and fat mass $1.21 \pm 0.11 \mathrm{~g}$, CVS mice body weight $27.26 \pm 0.47 \mathrm{~g}$ and fat mass $1.06 \pm 0.13 \mathrm{~g}, n=7-8)$. However, there were no significant differences in body weight gain (Fig. 4a) or fat mass between the CVS mice $(n=8)$ and the control mice $(n=8)$ on either diet (data not shown). The percentage of lean mass gain was significantly higher in the CVS mice consuming chow $(11.13 \pm 1.05 \%, n=8, p<0.01)$ and the high-fat diet $(7.86 \pm 1.9 \%, n=8, p<0.05)$ compared with the control mice consuming chow $(2.74 \pm 1.12 \%, n=7)$ and the high-fat diet $(2.54 \pm 1.2 \%, n=8$; Fig. $4 \mathrm{~b})$. The respiratory quotient was significantly decreased in the CVS mice $(0.77 \pm 0.01, n=15, p<0.01)$ compared with the control mice $(0.82 \pm 0.01, n=15)$ consuming chow, whereas respiratory quotient was unchanged in mice on the high-fat diet (Fig. 4c). There were no differences in food intake, energy expenditure and SPA among the groups $(n=7-8$; data not shown).

Chronic high-fat diet consumption impairs glucose metabolism in male mice previously exposed to CVS CVS mice consuming the high-fat diet had significantly lower plasma adiponectin $(2,308 \pm 172 \mathrm{pg} / \mathrm{ml}, n=8, p<0.05)$ and higher resistin $(5,093 \pm 687 \mathrm{pg} / \mathrm{ml}, n=8, p<0.05)$ compared with the control mice $(2,853 \pm 151 \mathrm{pg} / \mathrm{ml}$ and $2,816 \pm 388 \mathrm{pg} / \mathrm{ml}$, respectively, $n=8$ ), (Fig. $5 \mathrm{~d}, \mathrm{e})$. Interestingly, these differences in adiponectin and resistin preceded a significantly lower glucose tolerance observed in mice previously exposed to CVS ( $n=7$, two-way ANOVA, Tukey's post hoc test, $p<0.05)$, compared with the control mice $(n=8$; Fig. 5f). These differences depended on the combination of CVS exposure and subsequent exposure to the high-fat diet. There were no differences in adiponectin (Fig. 5a), resistin (Fig. 5b) or glucose tolerance (Fig. 5c) in mice consuming chow. At this stage of the study and therefore preceding the differences in glucose tolerance, there were no significant differences between the groups in fasting plasma insulin levels with the chow (control mice 208.1 $\pm 14.34 \mathrm{pmol} / \mathrm{l}$, CVS mice $224.1 \pm 20.27 \mathrm{pmol} / \mathrm{l}, n=7-8$ ) or the high-fat diet

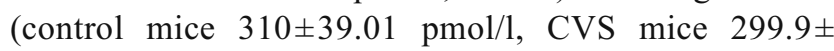
$45.68 \mathrm{pmol} / \mathrm{l}, n=7-8$ ).

The analysis of relevant genes in white adipose tissue from CVS mice on the high-fat diet using low-density array ( $n=4$, one-way ANOVA, Tukey's post hoc test) showed significantly higher expression of CCAAT/enhancer binding protein $(\mathrm{C} / \mathrm{EBP})$, beta (Cebpb; $p<0.01$; Fig. 6a), early growth response 2 transcription factor $(E g r 2 ; p<0.05$; Fig. 6b), hypoxia-inducible factor 1 alpha (Hifla; $p<0.05$; Fig. 6c) and chemokine (C-C motif) ligand 2 ( $\mathrm{Ccl} 2 ; p<$ 0.05 ; Fig. 6d) compared with the control/high-fat diet mice $(n=4)$. The expression of these genes indicates higher adipogenesis and adipocyte differentiation, hypoxia and inflammation, respectively, in accordance with the lower glucose tolerance observed in the CVS/high-fat diet mice.
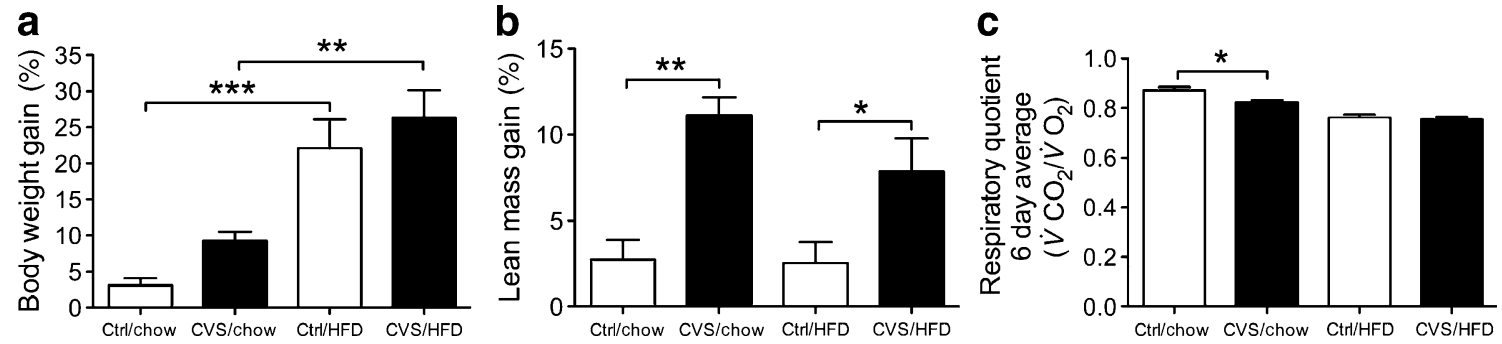

Fig. 4 Effects of chronic consumption of a high-fat diet after exposure to CVS on body composition in C57BL/6 male mice. Mice subjected to CVS and fed with chow or a high-fat diet (black bars, $n=$ 8 ) had a significantly higher percentage of lean mass gain compared with the control mice (white bars, $n=7-8$ ) (b) with no statistically significant changes in body weight gain (a). Mice subjected to CVS and fed with chow $(n=8)$ had a significantly lower 6 day average respiratory quotient compared with the control mice $(n=7)$, with no changes between the groups fed the high-fat diet $(n=8)(\mathbf{c})$. Two-tailed unpaired $t$ test and one-way ANOVA; Tukey's post hoc test $* p<0.05$. Ctrl, control; HFD, high-fat diet 

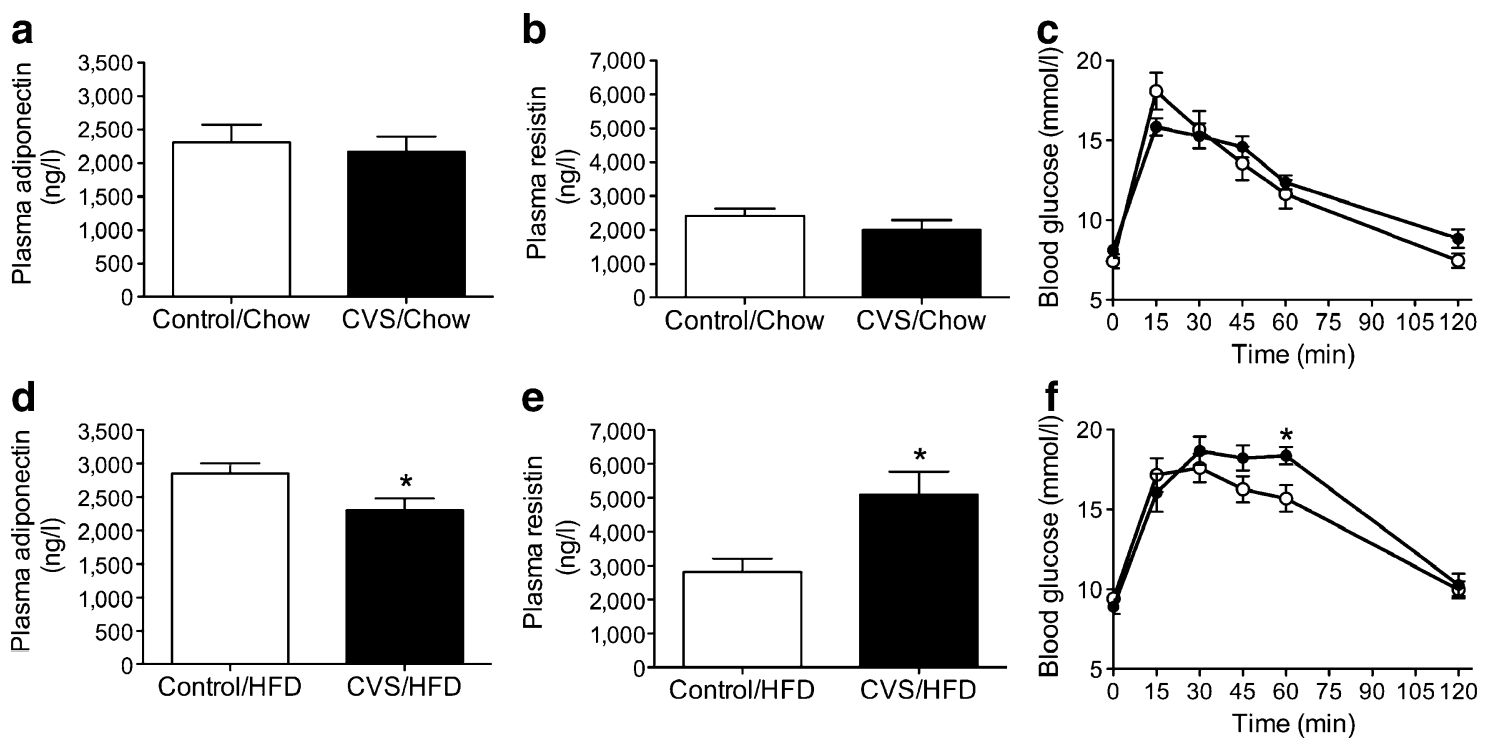

Fig. 5 Effects of high-fat diet after exposure to CVS on plasma adiponectin and resistin and on glucose tolerance in C57BL/6 male mice. Mice subjected to CVS and fed with the high-fat diet (black bars/circles, $n=7-8$ ) had significantly lower plasma adiponectin levels (d), higher plasma resistin levels (e) and significantly lower glucose tolerance (f) compared with the control/high-fat diet mice (white bars/

Mice fed chow did not differ in relation to CVS mice in the expression of the factors mentioned above $(n=4$; Fig. $6 \mathrm{a}-\mathrm{d})$. Mice subjected to CVS and fed with the high-fat diet $(n=3)$ showed higher lipogenesis as indicated by the significantly higher expression of glycerol kinase $(G y k)$ compared with $\mathrm{CVS} /$ chow mice $(n=4, p<0.05)$, but not when compared with control/high-fat diet mice $(n=4)$. Other specific gene targets involved in carbohydrate metabolism (Pdk2, Pdk4, Slc2al, Slc2a4), fatty acid synthesis (Pparg, Acaca, Fasn, Mlxipl, Scd1, Scd2), fatty acid transport (Cd36, Fabp4, Fabp5, Slc27a1), lipoprotein metabolism (Abcal, Apoe, Cd68, Ldlr, Lrp1, Scarb1), lipogenesis (Srebf1), lipolysis (Lipe, Lpl), inflammation (Il10, Itgax, Tnf), protein metabolism (Agt, Ppib), cytokine signalling (Adipoq, Atg4c, Lep, Retn), cell differentiation (Dlk1, Vegfa), cell adhesion/migration (Emrl), steroid metabolism (Abcgl, Hmgcr) and regulation of proliferation (Insig1) were not expressed at different levels in the CVS and the control groups.

CVS mice consuming the high-fat diet had significantly lower plasma NEFA $(0.07714 \pm 0.006 \mathrm{mmol} / \mathrm{l}, n=7, p<$ $0.05)$ compared with the control mice $(0.09625 \pm$ $0.005 \mathrm{mmol} / \mathrm{l}, n=8$; Fig. $6 \mathrm{~b}$ ) and lower plasma glycerol $(739.1 \pm 27.67 \mu \mathrm{mol} / \mathrm{l}, n=7, p<0.05)$ compared with the control mice $(901.2 \pm 59.58 \mu \mathrm{mol} / 1, n=8$; Fig. $6 \mathrm{~d})$. There were no differences in plasma NEFA (control $0.0675 \pm$ $0.01013 \mathrm{mmol} / 1$ vs CVS $0.0750 \pm 0.005345 \mathrm{mmol} / \mathrm{l}, n=8$ ) and glycerol (control $527.6 \pm 69.86 \mu \mathrm{mol} / \mathrm{l}$ vs. CVS $483.7 \pm$ $41.65 \mu \mathrm{mol} / 1, n=7-8$ ) between the groups consuming chow circles, $n=8$ ). Mice fed chow did not differ in relation to CVS in plasma adiponectin, resistin and glucose tolerance (chow-fed control mice, white bars/circles, $n=7$; chow-fed CVS mice, black bars/circles, $n=7-8)(\mathbf{a}-\mathbf{c})$. Two-tailed unpaired $t$ test and two-way ANOVA, Tukey's post hoc test $* p<0.05$

(Fig. 6a,c). There were no significant differences between the groups in fasting plasma insulin levels under chow (control mice $912.8 \pm 200.9 \mathrm{pmol} / \mathrm{l}$, CVS mice $637.5 \pm$ $112.9 \mathrm{pmol} / \mathrm{l}, n=6-8$ ) or with the high-fat diet (control mice $3,077 \pm 390.3 \mathrm{pmol} / \mathrm{l}$, CVS mice $4,815 \pm 1,656 \mathrm{pmol} / 1$, $n=7$; Fig. 6 e, f). There were no differences in plasma leptin levels with the chow (control mice 3.201 $\pm 1.047 \mu \mathrm{g} / \mathrm{l}$, CVS mice $2.730 \pm 0.3694 \mu \mathrm{g} / \mathrm{l}, \quad n=7-8)$ or the high-fat diet (control mice $39.19 \pm 6.552 \mu \mathrm{g} / \mathrm{l}$, CVS mice $47.52 \pm$ $10.01 \mu \mathrm{g} / \mathrm{l}, n=6-7$; Fig. $6 \mathrm{~g}, \mathrm{~h})$. Similarly, no significant differences were found: in plasma corticosterone levels between the groups with chow (control mice 222.8 \pm $26.19 \mathrm{nmol} / 1$, CVS mice $190.9 \pm 51.33 \mathrm{nmol} / 1, n=7-8)$ or the high-fat diet (control mice $227.4 \pm 27.91 \mathrm{nmol} / 1$, CVS mice $206.7 \pm 22.88 \mathrm{nmol} / 1, n=7-8)$; in plasma thyroidstimulating hormone with chow (control mice $0.0009156 \pm$ $0.0001525 \mathrm{mg} / \mathrm{l}$, CVS mice $0.001080 \pm 0.0003844 \mathrm{mg} / \mathrm{l}$, $n=7-8$ ) or the high-fat diet (control mice $0.0004667 \pm$ $0.0001080 \mathrm{mg} / \mathrm{l}$, CVS mice $0.0005617 \pm 0.0001139 \mathrm{mg} / \mathrm{l}$, $n=7-8$ ); or in total plasma $\mathrm{T}_{4}$ levels with chow (control mice $6,837 \pm 1,428 \mathrm{nmol} / \mathrm{l}$, CVS mice 5,187 $\pm 468.7 \mathrm{nmol} / 1, n=6$ 8 ) or the high-fat diet (control mice $4,537 \pm 1,178 \mathrm{nmol} / \mathrm{l}$, CVS mice 4,413 $\pm 644.6 \mathrm{nmol} / \mathrm{l}, n=6-7)$. Total plasma $\mathrm{T}_{3}$ levels were below the lower limit of detection in most of the samples.

As expected, the control $\left(5,341 \pm 559.2 \mu \mathrm{m}^{2}, n=5, p<0.01\right)$ as well as the CVS $\left(6,241 \pm 423.1 \mu^{2}, n=4, p<0.001\right)$ mice fed a high-fat diet had significantly increased adipocyte size compared with the chow-fed groups (control mice 1,711 

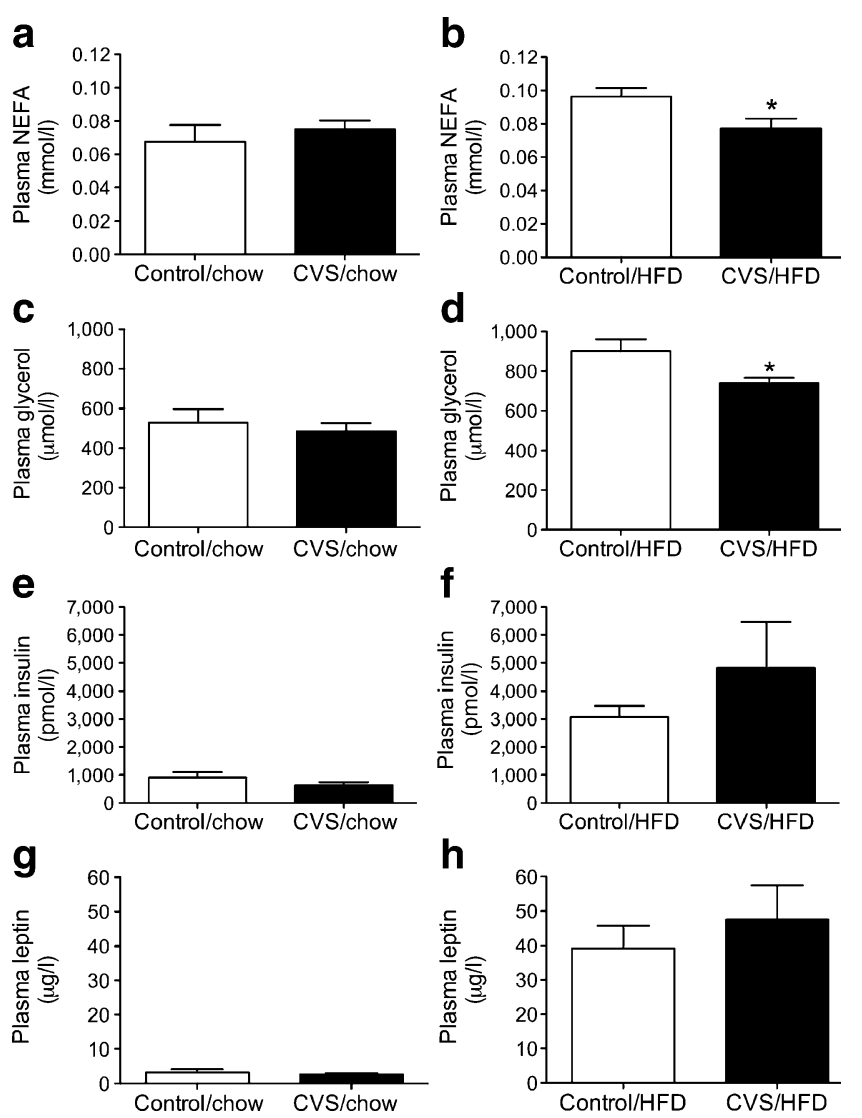

Fig. 6 Effects of CVS followed by chronic exposure to high-fat diet on plasma NEFA, glycerol, insulin and leptin in C57BL/6 male mice. Mice subjected to CVS and fed with the high-fat diet (black bars, $n=$ 7) had significantly lower plasma NEFA (b) and glycerol levels (d) compared with the control/high-fat diet mice (white bars, $n=8$ ). Mice fed chow did not differ in relation to CVS in plasma NEFA and glycerol $(n=8)(\mathbf{a}, \mathbf{c})$. Mice fed chow or high-fat diet did not differ in relation to CVS in plasma insulin and leptin $(n=6-8)(\mathbf{e}-\mathbf{h})$. Twotailed unpaired $t$ test $* p<0.05$

$\pm 275.4 \mu \mathrm{m}^{2}$, CVS mice $930.7 \pm 132.4 \mu \mathrm{m}^{2}, n=2-4$ ). There were no significant differences between the groups regarding CVS status (Fig. 7f).

CVS mice fed a high-fat diet actually had a significantly lower adrenal weight relative to total body weight $(0.005688 \pm 0.0002537 \%, n=5, p<0.01)$ when compared with CVS chow-fed mice $(0.009121 \pm 0.0007406 \%, n=7)$ at the time they were killed. There were no significant differences among the groups in relation to chow consumption, CVS status or when total adrenal weights were compared (data not shown).

\section{Discussion}

Chronic stress elicits neurochemical, neuroanatomical and cellular changes that may have serious health consequen- ces. For instance, chronic stress has been proposed to participate in the aetiology and progression of neurological disorders such as depression, anxiety and PTSD [34]. PTSD in particular is highly correlated with the incidence of obesity [17]. However, the molecular mechanisms underpinning PTSD-induced metabolic disorders are unknown.

Here, we characterise a mouse model in order to study the long-term effects of a discrete period of stress exposure on glucose homeostasis. Mice that were chronically stressed and subsequently fed a high-fat diet had impaired glucose tolerance as well as decreased white adipose tissue insulin sensitivity, as indicated by gene markers for adipogenesis, adipocyte differentiation, hypoxia and inflammation, compared with non-stressed mice fed the same diet, suggesting that prior stress exposure has long-term consequences for metabolic regulation. Interestingly, CVS mice fed the high-fat diet had lower circulating adiponectin and higher circulating resistin levels, suggesting that stressinduced imbalances in these two adipokines may contribute to the impairment of glucose metabolism.

The application of CVS to male mice resulted in lower plasma triacylglycerol levels, body weight, lean mass and SPA, consistent with previous reports regarding several different stressors $[2,35,36]$. The decrease in body weight in male mice seems to be mainly related to a parallel decrease in lean mass. This muscle wasting could be a consequence of the higher levels of corticosterone caused by the application of the stress, as documented in Cushing's disease and in rodents undergoing different stressors [2, 3739]; however, we did not find sustained differences in plasma corticosterone levels weeks, or even after the sustained stress exposure phase. This finding is consistent with our hypothesis that a metabolic impairment associated with PTSD is a late-onset consequence of re-programming rather than a direct and immediate result of higher HPAaxis activity. The decreased body weight was not accompanied by a decrease in adipose mass.

In addition to stress, another factor predisposing to the development of obesity and insulin resistance is exposure to a hyperenergetic environment typical of many western societies. Importantly, diet-induced obese mice are the most commonly used model for the study of polygenic obesity, as these mice share numerous features of obese patients. Although the effects of a high-fat diet in combination with a history of CVS are unknown, it is well established that chronic-restraint stress in rodents has a synergistic action on the HPA axis that translates into altered lipid metabolism and can lead to insulin resistance [24, 40]. Increased activity of the HPA axis with higher levels of circulating glucocorticoids opposes insulin action [41, 42], thereby potentially predisposing the organism to insulin resistance and its consequences. An association between the HPA axis 
a
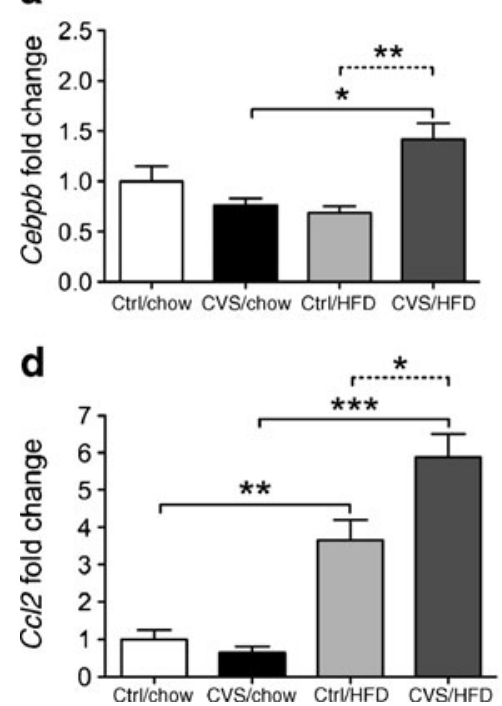

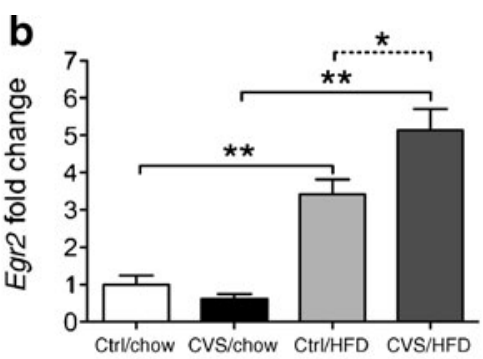

e

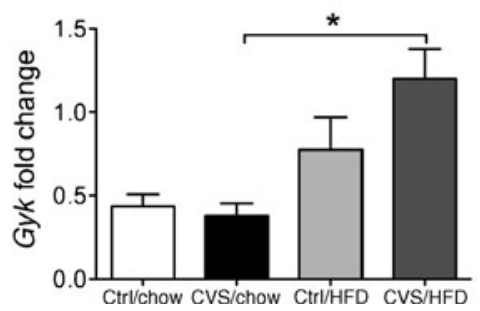

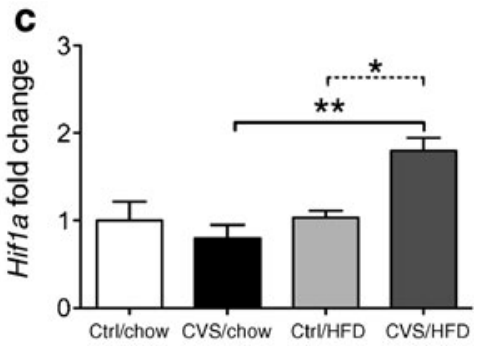

f

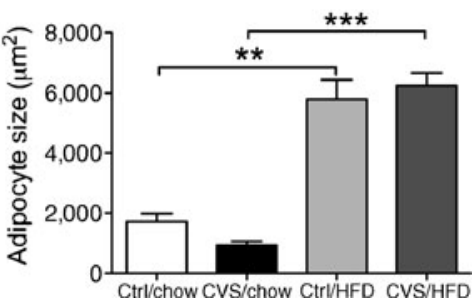

Fig. 7 Effects of CVS followed by chronic exposure to the high-fat diet on gene expression in white adipose tissue of C57BL/6 male mice. Mice subjected to CVS and fed with the high-fat diet (dark grey bars, $n=4$ ) show higher adipogenesis and adipocyte differentiation, hypoxia and inflammation as indicated by the significantly higher expression of CCAAT/enhancer binding protein (C/EBP), $\beta(C e b p b)$ (a), early growth response 2 transcription factor $(E g r 2)$ (b) hypoxiainducible factor $1 \propto$ (Hifla), (c) and chemokine (C-C motif) ligand 2 (Ccl2) (d) compared with the control/high-fat diet mice (light grey bars, $n=4)$. Mice fed chow did not differ in relation to CVS in the expression of the genes mentioned above (white and black bars, $n=4$ ) $(\mathbf{a}-\mathbf{c})$. Mice subjected to CVS and fed with the high-fat diet (dark grey bars, $n=3$ ) showed signs of increased lipogenesis as indicated by the significantly higher expression of glycerol kinase $(G y k)$ (e) and adipocyte size (f) compared with CVS/chow mice (black bars, $n=4$ 5) but not when compared with control/high-fat diet mice (light grey bars, $n=4)$. One-way ANOVA, Tukey's post hoc test $* p<0.05$, ** $p<$ $0.01, * * * p<0.001$ and energy balance has, for example, been observed in obese humans in whom dexamethasone, a synthetic glucocorticoid, and insulin synergistically activate lipoprotein lipase in adipose tissue, thereby facilitating fat deposition [43]. Therefore, we expected that consumption of a high-fat diet after exposure to chronic stress would promote the development of obesity and diabetes. Unexpectedly, however, our results indicate that the risk for the development of obesity does not differ from that in nonstressed mice fed the high-fat diet at the time they were killed.

Intriguingly, we discovered that insulin sensitivity is impaired in CVS/high-fat-fed mice. They were glucose intolerant and, consistent with that response, had lower adiponectin and higher resistin levels in the plasma. Adiponectin increases while resistin decreases [44-47] insulin sensitivity, consistent with the conclusion that the impaired glucose metabolism in CVS mice fed with a highfat diet may be mediated by these endocrine pathways, rather than directly resulting from increased HPA-axis activity. Another finding consistent with this hypothesis is that impaired glucose metabolism was apparent in mice consuming the high-fat diet but not in those fed low-fat chow (in which adiponectin and resistin levels were normal), in spite of both groups receiving CVS. We therefore propose that the levels of adiponectin and resistin are relevant for the development of insulin resistance in this case and are not secondary to increased plasma glucocorticoids, as previously implied [44-47].

Glucocorticoids have been found to inhibit adiponectin in vitro and in vivo, and adiponectin levels are decreased in Cushing's syndrome [48, 49]. Furthermore, glucocorticoids also stimulate resistin secretion [50]. As the impairment in glucose tolerance was present only in those CVS mice consuming the high-fat diet and not in CVS mice consuming chow, it is possible that glucocorticoids decreased adiponectin and increased resistin levels at the time of stress exposure. CVS mice subsequently fed with chow may have been able to recover to baseline levels of both hormones, while those on the high-fat diet may not.

White adipose tissue showed higher expression of genes that participate in the key processes of adipogenesis (Cebpb), adipocyte differentiation (Egr2), hypoxia (Hifla) and inflammation $(\mathrm{Ccl} 2)$ compared with the control/highfat-fed mice, indicating impaired insulin sensitivity and perhaps an early state of developing obesity in the CVS/ high-fat diet mice. In addition, plasma NEFA and glycerol levels were significantly lower, an indication of higher lipogenesis and fat synthesis. In addition, the CVS/high-fat diet mice showed higher expression of the glycerol kinase gene and adipocyte size, as indicators of lipogenesis, compared with the CVS/chow group. However, neither 
glycerol kinase expression nor adipocyte size were significantly different from the control/high-fat-fed mice. As with adiponectin and resistin, these differences in gene expression profiles, NEFA and glycerol levels between CVS and control mice were only observed following chronic exposure to a high-fat diet. Therefore, our findings might indicate that chronic exposure to a hyperenergetic environment post-CVS may enhance or maintain stress-induced metabolic damage.

In summary, our study demonstrates that exposure to a high-fat diet after a period of CVS can impair glucose tolerance without affecting overall body composition at the time. These findings are consistent with clinical observations of veterans returning from exposure to severe stress into a hyperenergetic and sedentary environment. Therefore, this new animal model may offer unique insights into the molecular mechanisms leading to PTSD-induced metabolic disorders.

Duality of interest The authors declare that there is no duality of interest associated with this manuscript.

\section{References}

1. Garden JM, O'Banion MK, Shelnitz LS et al (1988) Papillomavirus in the vapor of carbon dioxide laser-treated verrucae. JAMA 259:1199-1202

2. Tamashiro KL, Nguyen MM, Ostrander MM et al (2007) Social stress and recovery: implications for body weight and body composition. Am J Physiol Regul Integr Comp Physiol 293: R1864-R1874

3. Chrousos GP (2000) The role of stress and the hypothalamicpituitary-adrenal axis in the pathogenesis of the metabolic syndrome: neuro-endocrine and target tissue-related causes. Int J Obes Relat Metab Disord 24(Suppl 2):S50-S55

4. Kessler RC, Sonnega A, Bromet E, Hughes M, Nelson CB (1995) Posttraumatic stress disorder in the National Comorbidity Survey. Arch Gen Psychiatry 52:1048-1060

5. Resnick HS, Kilpatrick DG, Dansky BS, Saunders BE, Best CL (1993) Prevalence of civilian trauma and posttraumatic stress disorder in a representative national sample of women. J Consult Clin Psychol 61:984-991

6. Beckham JC, Roodman AA, Shipley RH et al (1995) Smoking in Vietnam combat veterans with post-traumatic stress disorder. J Trauma Stress 8:461-472

7. Hoge CW, Castro CA, Messer SC, McGurk D, Cotting DI, Koffman RL (2004) Combat duty in Iraq and Afghanistan, mental health problems, and barriers to care. N Engl J Med 351:13-22

8. Kang HK, Natelson BH, Mahan CM, Lee KY, Murphy FM (2003) Post-traumatic stress disorder and chronic fatigue syndrome-like illness among Gulf War veterans: a population-based survey of 30, 000 veterans. Am J Epidemiol 157:141-148

9. Marmar CR, Weiss DS, Schlenger WE et al (1994) Peritraumatic dissociation and posttraumatic stress in male Vietnam theater veterans. Am J Psychiatry 151:902-907

10. The Centers for Disease Control Vietnam experience Study (1988) Health status of Vietnam veterans. I. Psychosocial characteristics. JAMA 259(18):2701-2707
11. The Centers for Disease Control Vietnam Experience Study (1988) Health status of Vietnam veterans. II. Physical health. JAMA 259(18):2708-2714

12. The Centers for Disease Control Vietnam Experience Study (1988) Health status of Vietnam veterans. III. Reproductive outcomes and child health. JAMA 259:2715-2719

13. Weisberg RB, Bruce SE, Machan JT, Kessler RC, Culpepper L, Keller MB (2002) Nonpsychiatric illness among primary care patients with trauma histories and posttraumatic stress disorder. Psychiatr Serv 53:848-854

14. Goodwin RD, Davidson JR (2005) Self-reported diabetes and posttraumatic stress disorder among adults in the community. Prev Med 40:570-574

15. David D, Woodward C, Esquenazi J, Mellman TA (2004) Comparison of comorbid physical illnesses among veterans with PTSD and veterans with alcohol dependence. Psychiatr Serv $55: 82-85$

16. Kagan BL, Leskin G, Haas B, Wilkins J, Foy D (1999) Elevated lipid levels in Vietnam veterans with chronic posttraumatic stress disorder. Biol Psychiatry 45:374-377

17. Flegal KM, Carroll MD, Ogden CL, Johnson CL (2002) Prevalence and trends in obesity among US adults, 1999-2000. JAMA 288:1723-1727

18. Tsigos C, Young RJ, White A (1993) Diabetic neuropathy is associated with increased activity of the hypothalamic-pituitaryadrenal axis. J Clin Endocrinol Metab 76:554-558

19. Innes KE, Vincent HK, Taylor AG (2007) Chronic stress and insulin resistance-related indices of cardiovascular disease risk, part I: neurophysiological responses and pathological sequelae. Altern Ther Health Med 13:46-52

20. Oliver G, Wardle J, Gibson EL (2000) Stress and food choice: a laboratory study. Psychosom Med 62:853-865

21. Wardle J, Steptoe A, Oliver G, Lipsey Z (2000) Stress, dietary restraint and food intake. J Psychosom Res 48:195-202

22. Zellner DA, Loaiza S, Gonzalez Z et al (2006) Food selection changes under stress. Physiol Behav 87:789-793

23. Epel E, Lapidus R, McEwen B, Brownell K (2001) Stress may add bite to appetite in women: a laboratory study of stress-induced cortisol and eating behavior. Psychoneuroendocrinology 26:37-49

24. Tannenbaum BM, Brindley DN, Tannenbaum GS, Dallman MF, McArthur MD, Meaney MJ (1997) High-fat feeding alters both basal and stress-induced hypothalamic-pituitary-adrenal activity in the rat. Am J Physiol 273:E1168-E1177

25. Tsigos C, Chrousos GP (1996) Differential diagnosis and management of Cushing's syndrome. Annu Rev Med 47:443461

26. Marin P, Darin N, Amemiya T, Andersson B, Jern S, Bjorntorp P (1992) Cortisol secretion in relation to body fat distribution in obese premenopausal women. Metabolism 41:882-886

27. Nieuwenhuizen AG, Rutters F (2008) The hypothalamic-pituitaryadrenal-axis in the regulation of energy balance. Physiol Behav 94:169-177

28. Friedman TC, Mastorakos G, Newman TD et al (1996) Carbohydrate and lipid metabolism in endogenous hypercortisolism: shared features with metabolic syndrome X and NIDDM. Endocr J 43:645-655

29. Nogueiras R, Wiedmer P, Perez-Tilve D et al (2007) The central melanocortin system directly controls peripheral lipid metabolism. J Clin Invest 117:3475-3488

30. Pfluger PT, Kirchner H, Gunnel S et al (2008) Simultaneous deletion of ghrelin and its receptor increases motor activity and energy expenditure. Am J Physiol Gastrointest Liver Physiol 294: G610-G618

31. Choi DC, Evanson NK, Furay AR, Ulrich-Lai YM, Ostrander MM, Herman JP (2008) The anteroventral bed nucleus of the stria terminalis differentially regulates hypothalamic-pituitary- 
adrenocortical axis responses to acute and chronic stress. Endocrinology 149:818-826

32. Ostrander MM, Ulrich-Lai YM, Choi DC, Richtand NM, Herman JP (2006) Hypoactivity of the hypothalamo-pituitaryadrenocortical axis during recovery from chronic variable stress. Endocrinology 147:2008-2017

33. Furay AR, Bruestle AE, Herman JP (2008) The role of the forebrain glucocorticoid receptor in acute and chronic stress. Endocrinology 149:5482-5490

34. Reagan LP, Grillo CA, Piroli GG (2008) The As and Ds of stress: metabolic, morphological and behavioral consequences. Eur J Pharmacol 585:64-75

35. Molina VA, Heyser CJ, Spear LP (1994) Chronic variable stress or chronic morphine facilitates immobility in a forced swim test: reversal by naloxone. Psychopharmacology (Berl) 114:433-440

36. Fachin A, Silva RK, Noschang CG et al (2008) Stress effects on rats chronically receiving a highly palatable diet are sex-specific. Appetite 51:592-598

37. Pecori Giraldi F, Moro M, Cavagnini F (2003) Gender-related differences in the presentation and course of Cushing's disease. $\mathrm{J}$ Clin Endocrinol Metab 88:1554-1558

38. Roy RR, Gardiner PF, Simpson DR, Edgerton VR (1983) Glucocorticoid-induced atrophy in different fibre types of selected rat jaw and hind-limb muscles. Arch Oral Biol 28:639-643

39. Wajchenberg BL, Bosco A, Marone MM et al (1995) Estimation of body fat and lean tissue distribution by dual energy X-ray absorptiometry and abdominal body fat evaluation by computed tomography in Cushing's disease. J Clin Endocrinol Metab 80:2791-2794

40. Gounarides JS, Korach-Andre M, Killary K, Argentieri G, Turner O, Laurent D (2008) Effect of dexamethasone on glucose tolerance and fat metabolism in a diet-induced obesity mouse model. Endocrinology 149:758-766
41. Brown PD, Badal S, Morrison S, Ragoobirsingh D (2007) Acute impairment of insulin signalling by dexamethasone in primary cultured rat skeletal myocytes. Mol Cell Biochem 297:171-177

42. Sakoda H, Ogihara T, Anai M et al (2000) Dexamethasoneinduced insulin resistance in 3T3-L1 adipocytes is due to inhibition of glucose transport rather than insulin signal transduction. Diabetes 49:1700-1708

43. Fried SK, Russell CD, Grauso NL, Brolin RE (1993) Lipoprotein lipase regulation by insulin and glucocorticoid in subcutaneous and omental adipose tissues of obese women and men. J Clin Invest 92:2191-2198

44. Degawa-Yamauchi M, Bovenkerk JE, Juliar BE et al (2003) Serum resistin (FIZZ3) protein is increased in obese humans. J Clin Endocrinol Metab 88:5452-5455

45. Kubota N, Terauchi Y, Yamauchi T et al (2002) Disruption of adiponectin causes insulin resistance and neointimal formation. $\mathrm{J}$ Biol Chem 277:25863-25866

46. Maeda N, Shimomura I, Kishida K et al (2002) Diet-induced insulin resistance in mice lacking adiponectin/ACRP30. Nat Med 8:731-737

47. Youn BS, Yu KY, Park HJ et al (2004) Plasma resistin concentrations measured by enzyme-linked immunosorbent assay using a newly developed monoclonal antibody are elevated in individuals with type 2 diabetes mellitus. J Clin Endocrinol Metab 89:150-156

48. Degawa-Yamauchi M, Moss KA, Bovenkerk JE et al (2005) Regulation of adiponectin expression in human adipocytes: effects of adiposity, glucocorticoids, and tumor necrosis factor alpha. Obes Res 13:662-669

49. Fallo F, Scarda A, Sonino N et al (2004) Effect of glucocorticoids on adiponectin: a study in healthy subjects and in Cushing's syndrome. Eur J Endocrinol 150:339-344

50. Shojima N, Sakoda H, Ogihara T et al (2002) Humoral regulation of resistin expression in 3T3-L1 and mouse adipose cells. Diabetes 51:1737-1744 